\title{
Subakromiyal Sıkışma Sendromlu Hastalarda Peloidoterapinin Etkinliği
}

\author{
Müge KEPEKÇİ ${ }^{1}$, Özgür TAŞPINAR ${ }^{2}$, Yasemin BARUT ${ }^{3}$, İlker GEÇMEN $^{4}$
}

1 Sağlık Bilimleri Üniversitesi, İstanbul Kanuni Sultan Süleyman Eğitim ve Araştırma Hastanesi, Fiziksel Tıp ve Rehabilitasyon Kliniği, İstanbul.

2 Adakent Üniversitesi Sağlık Bilimleri Fakültesi, Fizyoterapi ve Rehabilitasyon Anabilim Dalı, İstanbul.

3 İstanbul Beylikdüzü Devlet Hastanesi, Tıbbi Ekoloji ve Hidroklimatoloji Kliniği, İstanbul.

4 Sağlık Bilimleri Üniversitesi, İstanbul Kanuni Sultan Süleyman Eğitim ve Araştırma Hastanesi, Tıbbi Ekoloji ve Hidroklimatoloji Kliniği, İstanbul.

\section{ÖZET}

Çalışmamızın temel amacı subakromiyal sıkışma sendromunda evde uygulanan ve hastanede uygulanan peloidoterapinin etkinliği araştırmaktır. Tek taraflı omzunda subakromiyal sıkıșma sendromu tanısı almış olan 73 kadın hasta çalıșmaya alındı. Hastalar tedavi grubu (n=42) ve kontrol grubu (n=31) olmak üzere iki farklı gruba ayrıldı. Tedavi grubundaki hastalara peloid tedavisi deriye direk temas olacak şekilde peloidoterapi ünitesinde uygulandı. Kontrol grubundaki hastalar ise peloidi evde kendi imkanlarıyla uyguladı. Her iki grup rutin medikal tedavilerine ve ev egzersiz programlarına devam ettiler. Değerlendirilmelerde hastaların omuz fonksiyonların değerlendirmek için DASH-T (Kol,omuz ve el yaralanması anketi) skorları, ağrı için VAS(Visuel Ağrı Skalası) ve genel durumları için sağlık değerlendirme anketi HAQ(Sağlı Değerlendirme Anketi) kullanıldı. Çalışma grubunda DASH ve HAQ skorları bakımından tedavi sonrasında tedavi öncesine göre anlamlı farklılık görülmemiştir (p\&gt;0.05). Yaptığımız çalışmada çalışma grubundaki peloidoterapi uygulamalarında kontrol grubundaki peloidoterapi uygulamalarına göre ağrı parametrelerinde daha olumlu sonuçlar elde edilmiștir. İleride yapılacak vaka sayısının arttırıldığ çalışmalara ihtiyaç vardır.

Anahtar Kelimeler: Subakromiyal Sıkışma Sendromu. Ağrı. Peloidoterapi.

Efficacy of Peloidotherapy in Patients with Subacromial Impingement Syndrome

\begin{abstract}
The main purpose of our study is to investigate the efficacy of peloidotherapy applied at home in subacromial impingement syndrome and applied at the hospital. 73 female patients who were diagnosed with subacromial impingement syndrome were enrolled on one-sided shoulder. The patients were divided into two different groups, the treatment group $(n=42)$ and the control group ( $=31)$. Peloid therapy was performed in the Peloid therapy unit to direct contact with the skin in patients with treatment group. The patients in the control group applied the Peloid therapy at home with their own facilities. Both groups continued their routine medical treatment and home exercise programs. In the evaluation, DASH-T (Disabilities of the Arm, Shoulder and Hand) scores were used to assess the patient's shoulder functions..VAS (Visual Analogue Scale) was used for pain and health Assessment Questionnaire HAQ (Health Assessment Questionnaire) was used for general conditions.In the study group, in terms of DASH and HAQ scores, there was no significant difference after treatment (P \&gt; 0.05).In the study of Peloidotherapy in the study group, more positive results were obtained in pain parameters according to peloidotherapy applications in the control group. Studies are needed to increase the number of cases in the future.
\end{abstract}

Key Words: Subacromial impingement Syndrome. Pain. peloidotherapy.

Geliş Tarihi: 06 Eylül 2018

Kabul Tarihi: 18 Aralık 2018

Dr. Müge KEPEKÇi

Sağlık Bilimleri Üniversitesi,

İstanbul Kanuni Sultan Süleyman Eğitim ve

Araștırma Hastanesi,

Fiziksel Tıp ve Rehabilitasyon Kliniği,

İstanbul.

Tel.: 05306979939

E-posta: dr.mugekepekci@gmail.com
Subakromiyal sıkışma sendromu (SSS); supraspinatus tendonunun, bisipital tendon ve subakromiyal bursanın humerus ile korokoakromial ark arasında sıkışması sonucu gelişir. Omuz ağrısının en sık nedenlerinden biridir. Araştırmalara göre rotator kaf lezyonları, \%9095 oranında aşırı kullanma, aşırı yüklenme ve mikro travmalara bağhlıdır ${ }^{1}$.

SSS'nin tedavisi mümkün olduğunca erken; çoğunlukla ağrı ve eklem sertliğini azaltmak, kas gücünü art- 
tırmak, problemlerin ilerlemesini önlemek, omuz fonksiyonunu en üst düzeye taşımak ve kişiyi günlük aktivitelere adapte etmek amacıyla konservatif yöntemlerle gerçekleştirilmektedir ${ }^{2}$. Bu konservatif yöntemler, rotator manşet ve skapular kaslar için egzersiz programları, çeşitli ilaçlar, manüel terapi teknikleri, günlük aktivitelerin modifikasyonu ve çeşitli fizik tedavi modalitelerini içerir ${ }^{3}$.

Genel uygulamada, fizik tedavi ve rehabilitasyon genellikle yumuşak doku ağrısını hafifletmek için 1sı uygulamasıyla başlar ve farklı elektroterapi yöntemleri ile devam eder. Transkutanöz elektriksel sinir uyarımı (TENS), interferansiyel akım ve ultrason ağrıyı kontrol etmek, kan dolaşımını arttırmak ve hastayı egzersize hazırlamak için en popüler uygulamalardır ${ }^{4}$.

Peloidoterapi; jeolojik ve biyolojik olaylar sonucu oluşan organik ve inorganik maddeler olan peloidlerin (tıbbi çamur) banyo, paket, sarma ve maske şeklinde uygulanmalarıyla yapılan bir tedavi yöntemidir. Balneoterapi, mineraller içeren sıcak veya 1 lık sularla terapidir, banyo olarak uygulanan fiziksel ve kimyasal özelliklere sahip olup, uygulandığında mekanik, kimyasal ve fiziksel etkiler oluşturur. Doğal dolaşım yoluyla meydana gelen termo-mineral sular, belirli bir sıcaklık seviyesine ulaşır ve bir dereceye kadar çözünmüş mineraller ve materyaller içerir, ayrıca özel kimyasal bileşime sahiptir. Termo-mineralli sular yeraltından yüzeye kendiliğinden veya suni yöntemlerle sondajla ortaya çıkar. Peloidoterapi ve balneoterapi yıllardan beri çeşitli kas iskelet sistemi bozukluklarında tedavide kullanılagelmiştir ${ }^{5,6}$.

Çalışmamızın temel amacı subakromiyal sıkışma sendromunda evde uygulanan ve hastanede uygulanan peloidoterapinin etkinliği araştırmaktır.

\section{Gereç ve Yöntem}

Çalışmamız randomize, prospektif, kontrollü, tek kör olarak Tibbi Ekoloji ve Hidroklimatoloji bölümünde Peloid Ünitesinde yapıldı. Randomizasyon yapılırken rastgele sayılar tablosu kullanılarak (tek sayılarda çalışma grubu, çift sayılarda kontrol grubu) olacak şekilde hastalar gruplara dağıtıld ${ }_{1}$ Çalışmaya tek taraflı omuzunda subakromiyal sıkışma sendromu tanısını manyetik rezonans görüntülemeyle almış olan, Neer sınıflandırmasına göre evre 1 ve evre 2 fibrozis ve tendinitin eşlik ettiği (ödem ve hemorajinin olmadığı) hastalar dahil edildi. Çalışmayı subakromiyal sıkışma sendromu olan 73 kadın hasta tamamlayabildi (Şekil $1)$.

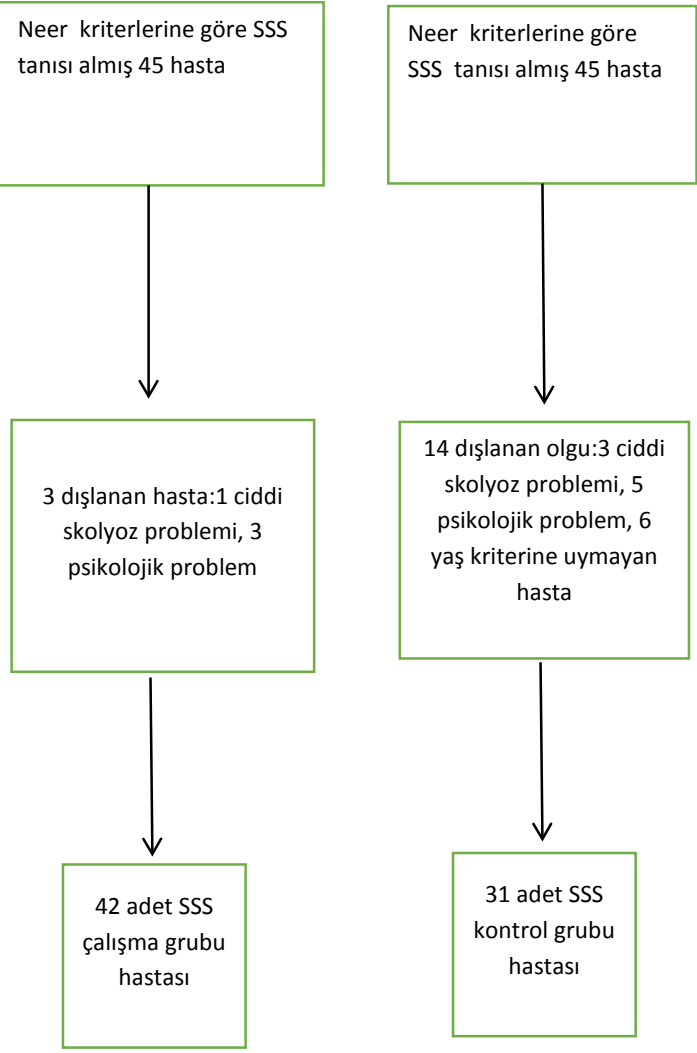

Şekil 1.

Çalışma akış şeması

Hastalar çalışmanın yürütüldüğü Mayıs 2018 ve Ağustos 2018 tarihleri arasında tedavi grubu $(n=42)$ ve kontrol grubu $(n=31)$ olmak üzere iki farklı gruba randomize edildi. Tüm hastaların demografik verileri, dominant kullandıkları elleri, etkilenen omuzun sağ mı sol mu olduğu kaydedildi.

Tedavi grubundaki hastalara 2 hafta süreyle haftanın 5 günü toplam 10 seans, 20 dakika $42^{\circ} \mathrm{C}$ sicaklıktaki peloid paketleri deriye direk olarak peloid ünitesinde hemşire refakatinde uyguland. Kontrol grubundaki hastalara ise 2 hafta süreyle haftanın 5 günü toplam 10 seans, 20 dakika $42^{\circ} \mathrm{C}$ sicaklıktaki peloid paketi evde hasta refakatçisi gözetiminde kendi imkanlarıyla uygulandı. Peloidin Tuzla Kaplıcaları yöresine ait peloid olduğu ve içeriğindeki peloidin mineralizasyonunun $3406 \mathrm{mg} / \mathrm{L}$ olmasına özen gösterildi. Her iki grup rutin medikal tedavilerine, oral $750 \mathrm{mg}$ naproksen alımına ve günde üç kere topikal naproksen cilt üzeri uygulamasına devam ettiler. Tüm hastalar günde 3 defa ev egzersiz programlarına devam ettiler. Günlük yaşam aktiviteleri düzenlendi, özellikle baş seviyesinin üzerindeki hareketlerden kaçınılması yaşam şekli modifikasyonu öğretildi. Tüm hastalara eklem hareket açıklığı egzersizleri, Codman'ın pandüler egzersizleri, germe egzersizleri, omuz çevresi kasları güçlendirmeye yönelik egzersizleri gösterildi. 
Endokrinolojik, romatolojik, immünolojik veya sistemik ko-morbid hastalığı olanlar nörolojik defisite neden olabilecek kronik sistemik ek hastalık öyküsü bulunanlar, travma, yer kaplayıcı lezyonları olan, omuz instabilitesi olanlar, omuz boyun torakal bölgeye yonelık geçirilmiş cerrahi operasyon veya son altı ayda uygulanmış enjeksıyonu olanlar, bes dereceyı gecen skolyozu, kifozite ve/veya farklı postur bozuklukları saptananlar, disk herniasyonu tanımlayanlar, majör travma öyküsü olanlar, poliakrilat ve benzer yapıdaki maddelere alerjisi olduğu bilinenler, geçirilmiş malignite öyküsü olanlar, uygulama yapılacak bölgede aktif selülit, deri irritasyonu, açık yaralar, derin ven trombozu veya varisi olan hastalar, ciddi kardiyak ve psikiyatrik sorunu olan hastalar, BMI 30'dan büyük olan obez hastalar, akut inflamasyon ve belirgin nörolojik defisiti saptananlar, servikal spinal ve/veya periferik sinirleri ilgilendiren nörolojik hastalığı olanlar, her iki omuzunda şikayeti olanlar, anatomik varyasyona sahip omuzlar, son altı ayda fizik tedavi-elektroterapi almış olanlar, glenohumeral osteoartrit, adeziv kapsüliti olanlar dışlanmıştır

Hastalar başlangıçta yani tedavi öncesi ve ilk değerlendirmeden 30 gün sonra yani kısa dönem sonuç olmak üzere toplamda iki kere hangi hastanın hangi grupta olduğunu bilmeyen değerlendiriciler tarafindan değerlendirilecekler. Sonuçlar kısa dönem yani 30 günlük sonuçları yansıtmaktadır. Değerlendirilmelerde hastaların omuz fonksiyonlarını değerlendirmek için Kol Omuz ve El Sorunları Anketi DASH-T skorlar1, ağrı için VAS ve genel durumları için sağlık değerlendirme anketi HAQ kullanıldı. Kol Omuz ve El Sorunları Anketinde her bir bölümde 0 hiç özür yok 100 maksimum özür var demektir. VAS skorları 0 ile 10 arasında değişmektedir. Sıfır hiç ağrım yok on ise bir insanın hayatında hissettiği en şiddetli ağrı olarak tanımlanmıştır. Sağlık Değerlendirme Anketinde en fazla skor 60 en az skor 0 olabilir. Skor arttıkça günlük aktivitelerde kişinin bağımsızlığı azalır.

Çalıșmaya alınan olgular çalışmaya katılmadan önce bilgilendirilmiş onam formlarını imzaladı. Çalışmayla ilgili yerel Etik Kurul onay belgesi edinildi. Tüm deneklerden gruplara rastgele atama için onay alındı.

\section{İstatistiksel Analiz}

Çalışmada verilerin normal dağılıma uygunluğu Shapiro Wilks testi ile test edilmiştir. Normal dağılım gösteren değişkenler için gruplar arası karşılaştırmalar $\mathrm{t}$ testi ve paired $\mathrm{t}$ testi ile, normal dağılmayan değişkenler için ise Mann Whitney testi ve Wilcoxon testi ile yapılmıştır. Parametrik testlerin uygulanması durumunda betimleyici değerler ortalama \pm standart sapma olarak, non-parametrik testlerin kullanılması durumunda ise medyan(min:max) olarak verilmiştir. Kategorik değişkenlerin karşılaştırılmasında chisquare, Fishers exact test ve Fisher-Freeman- Halton testi ile yapılmıştır. Kategorik veriler n(\%) olarak verilmiştir. İstatistiksel anlamlılık düzeyi olarak $\alpha=0.05$ alınmıştır.

\section{Bulgular}

Grupların demografik bilgilerini karşılaştırdığımızda yaş, BMI, sigara ve alkol kullanımı, baskın olan el, etkilenen omuz, medeni durum bakımından gruplar homojendir ( $\mathrm{p}>0.05)$ (Tablo-I). Tedavi öncesi başlangıç değerleri VAS, HAQ ve DASH skorları bakımından da gruplar homojendir ( $\mathrm{p}>0.05$ ) (Tablo-I).

Tablo I. Gruplar arasında homojenite karşılaştırmaları ve betimleyici değerleri

\begin{tabular}{|c|c|c|c|}
\hline Değişkenler & $\begin{array}{c}\text { Çalışma } \\
(n=42)\end{array}$ & $\begin{array}{l}\text { Kontrol } \\
(\mathrm{n}=31)\end{array}$ & $P$ \\
\hline Yaş [mean $\pm S D$ ] & $48.02 \pm 10.08$ & $48.13 \pm 8.94$ & 0.963 \\
\hline BMI [median(min:max)] & $23(19: 34)$ & $21(19: 30)$ & 0.280 \\
\hline Sigara içen [n (\%)] & $13(31.0)$ & $9(29.0)$ & 1.000 \\
\hline Alkol kullanan [n (\%)] & $9(21.4)$ & $9(29.0)$ & 0.638 \\
\hline Sağ dominant el [n (\%)] & $31(73.8)$ & $24(77.4)$ & 0.937 \\
\hline Sağ Etkilenen omuz [n (\%)] & $29(69.0)$ & $21(67.7)$ & 1.000 \\
\hline Medeni durum [n (\%)] & & & \\
\hline Bekar & $13(31.0)$ & $8(25.8)$ & 0.663 \\
\hline Evli & $26(61.9)$ & $22(71.0)$ & \\
\hline Dul & $3 \quad(7.1)$ & $1(3.2)$ & \\
\hline $\begin{array}{l}\text { Önce Vas [me- } \\
\text { dian(min:max)] }\end{array}$ & $5(2: 7)$ & $5(1: 9)$ & 0.655 \\
\hline $\begin{array}{l}\text { Önce Haq [me- } \\
\text { dian(min:max)] }\end{array}$ & $24.5(10: 45)$ & $31(1: 52)$ & 0.183 \\
\hline Önce Dash [mean $\pm S D$ ] & $16.02 \pm 6.52$ & $15.61 \pm 6.88$ & 0.796 \\
\hline
\end{tabular}

Çalışma grubuna baktığımızda VAS skorları bakımından tedavi sonrasında tedavi öncesine göre anlamlı bir azalma görülürken $(\mathrm{p}<0.001)$; DASH ve HAQ skorları bakımından anlamlı farklılık görülmemiştir $(\mathrm{p}>0.05)$ (Tablo-II)

Tablo II. Çalışma grubunda VAS, DASH ve HAQ ölçeklerinin tedavi öncesi ve sonrası karşılaştırılması

\begin{tabular}{|l|c|c|c|}
\hline \multicolumn{1}{|c|}{ Çalışma Grubu (n=42) } & $\begin{array}{c}\text { Tedavi } \\
\text { öncesi }\end{array}$ & $\begin{array}{c}\text { Tedavi } \\
\text { Sonrası }\end{array}$ & $P$ \\
\hline VAS [median(min:max)] & $5(2: 7)$ & $3(0: 7)$ & $<0.001$ \\
\hline DASH [mean $\pm S D]$ & $16.02 \pm 6.52$ & $15.26 \pm 6.54$ & 0.092 \\
\hline HAQ [median(min:max)] & $24.5(10: 45)$ & $21.5(3: 45)$ & 0.043 \\
\hline
\end{tabular}

Kontrol grubuna baktığımızda VAS skorları bakımından tedavi sonrasında tedavi öncesine göre anlamlı bir azalma görülmüştür $(\mathrm{p}<0.001)$ (Tablo-III) 
Tablo III. Kontrol grubunda VAS, DASH ve HAQ ölçeklerinin tedavi öncesi ve sonrası karŞılaştırılması

\begin{tabular}{|l|c|c|c|}
\hline \multicolumn{1}{|c|}{ Kontrol grubu $(\mathrm{n}=31)$} & Tedavi öncesi & Tedavi Sonrası & $\mathrm{P}$ \\
\hline VAS [median(min:max)] & $5(1: 9)$ & $4(0: 8)$ & $<0.001$ \\
\hline DASH [mean \pm SD] & $15.61 \pm 6.88$ & $15.19 \pm 7.30$ & 0.469 \\
\hline HAQ [mean $\pm S D]$ & $30.23 \pm 12.94$ & $29.23 \pm 13.77$ & 0.157 \\
\hline
\end{tabular}

Kontrol grubunda DASH ve HAQ skorları bakımından tedavi sonrasında tedavi öncesine göre anlaml farklılık görülmemiştir ( $\mathrm{p}>0.05)$ (Tablo-III) VAS skorunda, çalışma grubunda son ölçümde ilk ölçüme göre 2 puanlık azalış olmuştur. Çalışma grubundaki değişim bakımından ise VAS skoru hiç değişmeyen hastalar olmakla birlikte, VAS skorunda 5 puanlık azalma olan hastalar görülmüştür. Kontrol grubunda ise 1 puanlık azalma görülmekle birlikte, VAS skoru hiç değişmeyen hastalar ve 3 puanlık azalma olan hastalar görülmektedir. Çalışma grubunda kontrol grubuna göre tedavi sonrasında VAS skorunda azalma daha fazladir ve istatistiksel olarak anlaml1$\operatorname{dir}(p=0.004)$ (Tablo-IV).

Tablo IV. VAS, DASH ve HAQ ölçekleri için son değerlendirme ve ilk değerlendirme arasındaki değişimim (fark skoru=son-ilk) gruplar arasında karşılaştırılması

\begin{tabular}{|l|c|c|c|}
\hline Skorlar [median(min:max)] & Çalışma $(n=42)$ & Kontrol $(n=31)$ & $P$ \\
\hline Vas & $-2(-5: 0)$ & $-1(-3: 0)$ & 0.004 \\
\hline Dash & $0(-11: 5)$ & $0(-10: 10)$ & 0.773 \\
\hline Haq & $0(-20: 0)$ & $0(-20: 0)$ & 0.723 \\
\hline
\end{tabular}

DASH ve HAQ skorları bakımından son ölçümde ilk ölçüme göre değişim bakımından anlamlı bir farklılık görülememiştir ( $\mathrm{p}>0.05)$ (Tablo-IV).

\section{Tartışma}

Çalışmamızın en önemli sonucu hastane ve evde uygulanan peloidoterapi uygulamalarında hastane grubunda uygulayan hastaların VAS skorlarında evde uygulayanlara göre anlamlı oranda azalma gözlenmiştir. Ancak DASH-T ve HAQ skorlarında anlamlı bir fark saptanmamıştır. Çeşitli nedenlerle hastaneye gelemeyen hastaların peloid tedavisi sonunda varolan ağrısındaki azalma; hastanede peloid ünitesinde tedavi alanlara göre istatistiksel olarak anlamlı derecede azdir.

Tefner ve ark nın yaptığı kronık omuz ağrlı 46 hastalık bir çalışma yapmışlar. Hastalar 23'er kişilik iki tedavi grubuna ayrılmış. Kontrol grubuna fizik tedavi seanslarına girmiş, diğer gruba da balnaoterapi uygulanmış. Çalışmanın sonuçlarına baktığımızda iki grup- ta da ağrı ve fonksiyonellik skorlarında iyileşme saptanmıştır. Balneoterapi grubundaki değişiklikler daha fazla olduğu görülmüştür ${ }^{8}$. Bizim çalışmamızda hastalarımızın VAS değerlerinde hastane peloidoterapi grubundaki değişiklikler ev peloidoterapi grubuna göre daha fazla azalmıştır. Ancak bizim çalışmamızda fonksiyonel durumlarda anlamlı bir değişiklik saptanmamıştır.

Şen ve ark'nın yaptığı subakromial sıkışma sendromlu 29 hastalık bir çalışmada hastalara $45^{\circ} \mathrm{C}$ sıcaklığında ve 30 dakika süre ile günde bir seans lokal peloid paket uygulandı. Tedaviye hafta içi beş gün olarak üç hafta15 seans devam edildi Ağrının şiddetini değerlendirmek için Görsel Analog Skala (VAS) ve omuz fonksiyonlarını değerlendirmek için Constant, UCLA ve Omuz Özürlülük Skorlaması (OÖS) kullanıldı. Hastalar tedavi öncesi, tedavi sonrası ve üçüncü ayın sonunda yeniden değerlendirildi. Tedavi sonrası ve üçüncü ayın sonundaki kontrollerde VAS, Constant, UCLA, OÖS parametrelerinde anlamlı düzelme saptandı ${ }^{9}$. Ağrı durumlarındaki değişiklik çalışmamızla uyumludur.

Kas iskelet sistemi hastalıklarında kullanılan balneoterapinin bir çeşidi olan peloidoterapi ile ilgili yüz güldürücü sonuçlar elde edilmektedir. Yurdumuzda balneoterapi ve peloidoterapi açısından zengin bir ülkedir. Peloidoterapi ağrıyı iyileştirmekte ve hastalıkların akut fazlarını önlemektedir. Peloidoterapi termal uyarı sonucu noradrenalin, kortizol ve b-endorfinlerin serum seviyelerini ve doku düzeylerini arttırarak antienflamatuar ve analjezik etki oluşturur ${ }^{10}$. Uygulama sırasında derin kaslarda kan akımı artar, dokulardaki artmış oksijen sonucu kemik, eklem ve dokularda iyileşme patansiyeli $\operatorname{artar}^{11}$. Ayrıca balneoterapi ve peloidoterapinin anksiyete ve depresyon üzerine de yararlı etkileri vardır. Bunlara dayalı olarak da ağrı ve fonksiyonellikte ilerlemeler kaydedilmiştir ${ }^{12}$.

Şen ve ark'nın diz osteoartritli ve kronik bel ağrılı hastalarda yapmış olduğu çalışmalarda da lokal peloid uygulamalarının ağrı ve fonksiyonel durum parametrelerinde anlamlı düzelmeler sağladığı ve yaşam kalitesini arttıran bir yöntem olarak güvenle kullanılabileceği sonucuna varılmıştır ${ }^{13,14}$.

Peloidoterapi hidroklimatoloji kliniklerinde kullanılmasına rağmen ülkemizde bu tür kliniklerin sayısı azdır. Bu tedavinin olumlu sonuçları günden güne çeşitli yayınlarla kanıtlanmaktadır. Fizik tedavi kliniklerimizde kullanımı kısıtlıdır. Bu açıdan bu tedaviye olan farkındalığın artırılarak standart tedavi protokollerine alternatif tamamlayıcı tedavi yöntemi olarak eklenmesi yerinde olacaktır. Yaptığımız çalışmada hastane grubundaki peloidoterapi uygulamalarında ev peloidoterapi uygulamalarına göre daha olumlu sonuçlar elde edilmiştir. Çalışmamız çok küçük bir örneklem üzerinde kısa dönem sonuçları değerlendirmiştir, bu ve benzeri çalışmaların vaka sayısı artırılarak uzun dönem çalışmalarla desteklenmesi uygun olacaktır. 


\section{Subakromiyal Sıkışma Sendromunda Peloidoterapi}

\section{Kaynaklar}

1. Akgün K. [Shoulder Pains]. In: Tüzün F, Eryavuz M, Akarırmak Ü, eds. Hareket Sistemi Hastalıkları. 1st ed. Istanbul: Nobel Tip Bookstores; 1997. p.193-210

2. Cools MA, Johansson FR, Borms D, Maenhout A. Prevention of shoulder injuries in overhead athletes: a science-based approach. Braz J Phys Ther, 2015;19 (5): 331-339.

3. Dong $\mathrm{W}$, Goost $\mathrm{H}$, Lin XB, et al. Treatments for shoulder impingement syndrome Medicine, 2015; 94 (10): 1-17.

4. Yuruk O. Omuz Rehabilitasyonunda Kullanılan Fiziksel Ajanlar ve Elektroterapi Yöntemleri. G. Baltacı (Ed.), Omuz Yaralanmalarında Rehabilitasyon, Pelikan Yayıncılık, Ankara, 2015.

5. M.Z. Karagulle, Thermal, mineral and thermo-mineral waters "for hot springs, in: Balneologia and Thermal Spring Medicine, M.Z. Karagulle, ed., (Turkish book) Nobel press, Istanbul, 2002, pp. 37-50.

6. Franke A, Reiner L, Pratzel HG, Franke T, Resch KL. Longterm efficacy of radon spa therapy in rheumatoid arthritis-a randomized, sham-controlled study and follow-up. Rheumatology (Oxford.) 2000;39: 894-902.

7. Düger T, Yakut E, Öksüz Ç, Yörükan S, Bilgütay BS, Ayhan Ç, ark. Kol, omuz ve el sorunları anketi Türkçe uyarlamasının güvenilirliği ve geçerliği. Fizyoterapi Rehabilitasyon. 2006;17(3):99,107.
8. Tefner IK, Kovács C, Gaál R, Koroknai A, Horváth R, Badruddin RM, Borbély I, Nagy K, Bender T. The effect of balneotherapy on chronic shoulder pain. A randomized, controlled, single-blind follow-up trial. A pilot study. Clin Rheumatol. 2015 Jun;34(6):1097-108. doi: 10.1007/s10067-013-2456-3. Epub 2013 Dec 17

9. Şen U, Karagülle M, Erkorkmaz Ü. Subakromial Sıłışma Sendromlu Hastalarda Balneoterapinin Etkinliği. Turkiye Klinikleri J Med Sci 2010;30(3).

10. Bender T, Karagülle Z, Bálint GP, Gutenbrunner C, Bálint PV, Sukenik S. Hydrotherapy, balneotherapy, and spa treatment in pain management. Rheumatol Int 2005;25(3):220-4.

11. Becker BE (2009) Aquatic therapy: scientific foundations and clinical rehabilitation applications. PM R 1:859-872

12. Dubois O, Salamon R, Germain C, Poirier MF, Vaugeois C, Banwarth B, Mouaffak F, Galinowski A, Olié JP. Balneotherapy versus paroxetine in the treatment of generalized anxiety disorder. Complement Ther Med 2010;18:1-7.

13. Şen U, Karagülle M.Z, Karagülle M. The efficacy of peloidotherapy on knee osteoarthritis. Türk Romatoloji Derg 2007;(2)22:55-9.

14. Şen U, Karagülle M.Z, Karagülle M, Erkorkmaz Ü. [The efficacy of peloidotherapy on the patients with chronic low back pain]. Türkiye Klinikleri J Med Sci 2008;28(1):5-11. 
